\title{
Risk factors assessment of bovine tuberculosis among abattoir personnel in Gombe State, Northeastern Nigeria: A One-Health approach
}

\author{
S. Mohammed ${ }^{1}$, Adamu Saleh Saidu' ${ }^{2,3}$, S. M. Jajere ${ }^{2,4}$, P. Tomar ${ }^{3}$, A. M. Wakil ${ }^{5}$, J. Mohammed ${ }^{1}$ and R. Preeti ${ }^{3}$
}

1. Department of Veterinary Public Health and Preventive Medicine, Faculty of Veterinary Medicine, Ahmadu Bello University, PMB 1013, Zaria, Kaduna State, Nigeria; 2. Department of Veterinary Public Health and Preventive Medicine, Faculty of Veterinary Medicine, University of Maiduguri, PMB 1069, Maiduguri, Nigeria; 3. Department of Veterinary Public Health and Epidemiology, College of Veterinary Sciences, Lala Lajpat Rai, University of Veterinary and Animal Sciences,

Hisar - 125 004, Haryana, India; 4. Department of Pathobiology and Microbiology, Faculty of Veterinary Medicine, Universiti Putra Malaysia, 43400 UPM Serdang, Selangor, Malaysia; 5. Department of Veterinary Physiology and Biochemistry, Faculty of Veterinary Medicine, University of Maiduguri, PMB 1069, Maiduguri, Nigeria. Corresponding author: Adamu Saleh Saidu, e-mail: adamudvm13@gmail.com

Co-authors: SM: msani600@gmail.com, SMJ: drmsjajere@unimaid.edu.ng, PT: tomarvety@gmail.com, AMW: amwakil@unimaid.edu.ng, JM: drjamilumohd@gmail.com, PR: rohillapreeti807@gmail.com, Received: 11-08-2018, Accepted: 04-12-2018, Published online: 09-01-2019

doi: 10.14202/IJOH.2019.1-8 How to cite this article: Mohammed S, Saidu AS, Jajere SM, Tomar P, Wakil AM, Mohammed J, Preeti R. Risk factors assessment of bovine tuberculosis among abattoir personnel in Gombe State, Northeastern Nigeria: A One-Health approach. Int J One Health 2019;5:1-8.

\begin{abstract}
Aim: Bovine tuberculosis (bTB) is an important milk-borne zoonosis that affects cattle production and poses serious threat to public health. This study aimed at assessing the risk factors as well as the level of awareness, attitude, and practices of abattoir personnel toward bTB in Gombe Township Abattoir, Gombe State.
\end{abstract}

Materials and Methods: A prospective survey was conducted between October 2015 and December 2015. During the survey, a total of 112 close-ended structured questionnaires were administered to the abattoir personnel to assess their level of awareness of bTB.

Results: Of these respondents, the majority were males (79\%), butchers (49\%) and about 40\% were under the productive age brackets of 26-35 years. Majority of the respondents (85.7\%) were aware of the zoonotic nature of the disease. However, only a few of the respondents $(44.6 \%)$ wear personal protective equipments (PPEs) clothes while handling or in contact with carcasses during the slaughtering process. Only a few among the respondents $(24.1 \%$ and $31.2 \%)$ consumed unpasteurized milk and unaware of eating of improperly cooked meat as a risk factor of bTB, respectively. About $75.7 \%$ of the respondents believed that the habit of eating and drinking inside the abattoir and during slaughtering operations has no any significant effects on their health. The results obtained show a statistically significant association between respondents' awareness of bTB and their occupational status, duration of exposure to cattle carcasses, and knowledge about the disease $(p<0.05)$; and the odds of being aware of bTB was 10.0, 5.07, and 4.2, respectively.

Conclusion: This study demonstrates the need for public health authorities to intervene in bTB prevention and control through the creation of avenues for enlightenment on the zoonotic risk associated with bTB. The risk factors associated with bTB transmission as indicated by the personnel's practice and awareness levels in Gombe township abattoir are preventable through the use of PPEs clothing.

Keywords: abattoir personnel, bovine tuberculosis, Gombe, one-health approach, risk factors.

\section{Introduction}

Bovine tuberculosis (bTB) is a contagious bacterial disease which is lethal to both human and animals, caused by Mycobacterium bovis, a member of the Mycobacterium tuberculosis complex (MTC) [1]. The organism is unique due to its wide host range and can infect all warm-blooded vertebrates [2-4]. It is one of the most common zoonotic diseases with global distribution particularly in developing countries such as Nigeria [5]. In Nigeria, the burden of bTB was first

Copyright: S. Mohammed, et al. This article is an open access article distributed under the terms of the Creative Commons Attribution 4.0 International License (http://creativecommons.org/ licenses/ by/4.0/), which permits unrestricted use, distribution, and reproduction in any medium, provided you give appropriate credit to the original author(s) and the source, provide a link to the Creative Commons license, and indicate if changes were made. The Creative Commons Public Domain Dedication waiver (http:// creativecommons.org/ publicdomain/zero/1.0/) applies to the data made available in this article, unless otherwise stated. reported by Alhaji [6]. Since then, various studies have reported the occurrence of the disease in different parts of the country and at different period of time. However, various work done by experts have reported varying incidences which ranging $0.78-26.6 \%$ from one part of the country to another, making it one of the endemic diseases across the country [2,7,8-11].

bTB is re-emerging in most developing countries including Nigeria, due to inadequate facilities and established control programs. However, the disease draws the attention of international community because it posed sustained threat on beef and dairy products as well as serious implications on public health, especially in developing countries such as Nigeria, where surveillance and control measures are weak or non-existent [12]. Postmortem meat inspection and abattoirbased studies provide an estimate of bTB prevalence and various authors at different times 
also reported its endemicity from both southern and northern parts of Nigeria $[5,13,14]$. The previous survey conducted in Nigeria established the presence of $M$. bovis both in pulmonary and extrapulmonary tuberculosis in human $[7,15,16]$.

M. bovis infection can be transmitted to humans through ingestion of contaminated, unpasteurized dairy products, direct contact with or inhalation of the bacteria in air exhaled by infected animals during the course of slaughter [17]. Even though direct transmission from animals to humans through the air is thought to be rare, $M$. bovis can be transmitted directly from person to person when people with the disease in their lungs cough or sneeze [18]. M. bovis has been incriminated together with MTC species as the cause of tuberculous lymphadenitis in humans [19]. The occurrence or spillover of bTB to humans or people at risk is increasing due to projectile increase in $\mathrm{HIV/}$ AIDS incidence in some developing countries where drinking raw milk is a common practice in most rural areas [20]. Thus, this portrays the threat of this disease to humans $[21,22]$.

The infection involves the formation of granulomas in organs, particularly the lungs, but it may spread to other organs such as lymph nodes, intestine, and kidney [23]. Animals often remain asymptomatic until the infection has reached an advanced stage [24]. The implications of tuberculosis on public health have been a life-threatening one, accounting to about 4 million deaths yearly worldwide; of which at least $3 \%$ are due to zoonotic tuberculosis [5]. Besides being a public health threat, it also has significant socioeconomic impacts particularly in beef and dairy industries [25]. To the best of our knowledge, there is a paucity of information on the risk assessments of zoonotic bTB among abattoir personnel in Gombe State. Even though various reports on the disease in the same study area have been published $[2,8,9,11]$.

Therefore, this study was designed to assess the awareness of bTB and its risk factors among abattoir personnel in Gombe Township Abattoir, Gombe State. It is expected that the outcome obtained from this study should serve as a baseline epidemiological data in assisting the government in making policies toward controlling bTB in northeastern region - which has the largest livestock population in the country, and by doing so, the government commitments in diversification of national economy in agriculture and livestock productions would be realized.

\section{Materials and Methods}

\section{Ethical approval and Informed consent}

This study involved the use of a "questionnaire interview", distributed among abattoir personnel. Therefore, prior to that, local approval was obtained from the Director, Veterinary services at the Ministry of Animal Husbandry and Nomadic Affairs, Gombe State, Nigeria. Informed consent has been obtained from all participants.

\section{Study area}

Gombe State occupies a total land area of $20,265 \mathrm{~km}^{2}$ representing about $2.2 \%$ of Nigeria's total land mass and is located between latitudes $9^{\circ} 301 \mathrm{~N}$ and $12^{\circ} 301 \mathrm{E}$ and longitudes $8^{\circ} 451$ and $11^{\circ} 451 \mathrm{E}$ [26]. Borno and Yobe States border the state to the east and north, respectively, Adamawa and Taraba to the south and the Bauchi States to the west (Figure-1). The wet season is from April to October and the dry season is from November to March. Gombe has a population density of 2,353,879 million people and ranked $33^{\text {rd }}$ of the 36 states [27]. The state has an estimated cattle population of $1,175,765$ million, which is about $1 \%$ of the estimated cattle population of 13,900,000 million [28]. The state comprises different ethnic groups including Fulfulde, Tangale, Tera, Kanuri, Waja, Bolewa, Hausa, Jukun, Tula, Cham, Dadiya, Pero, Lunguda, Kamo, and Awak. The state has 11 Local Government Areas, namely Akko, Balanga, Billiri, Dukku, Funakaye, Gombe, Kaltungo, Kwami, Nafada, Shongom, and Yamaltu/Deba [26]. The survey was carried out in Gombe Township abattoir, Gombe State.

\section{Structured questionnaire interviews}

A total of 112 close-ended structured questionnaires were developed using Epi info ${ }^{\mathrm{TM}}$ version 7.2.2.2 and administered to abattoir personnel. The questionnaire was developed based on the information gathered from literature and on the basis of the communities' attitude and practice. Only persons with a willingness to participate in the study were included. The questionnaire was prepared in English language but administered in the commonly spoken Hausa dialect ("Lingua franca") by face-to-face interview. The questionnaires focused on assessing the level of knowledge, attitude, and practices of bTB. Assessment of their

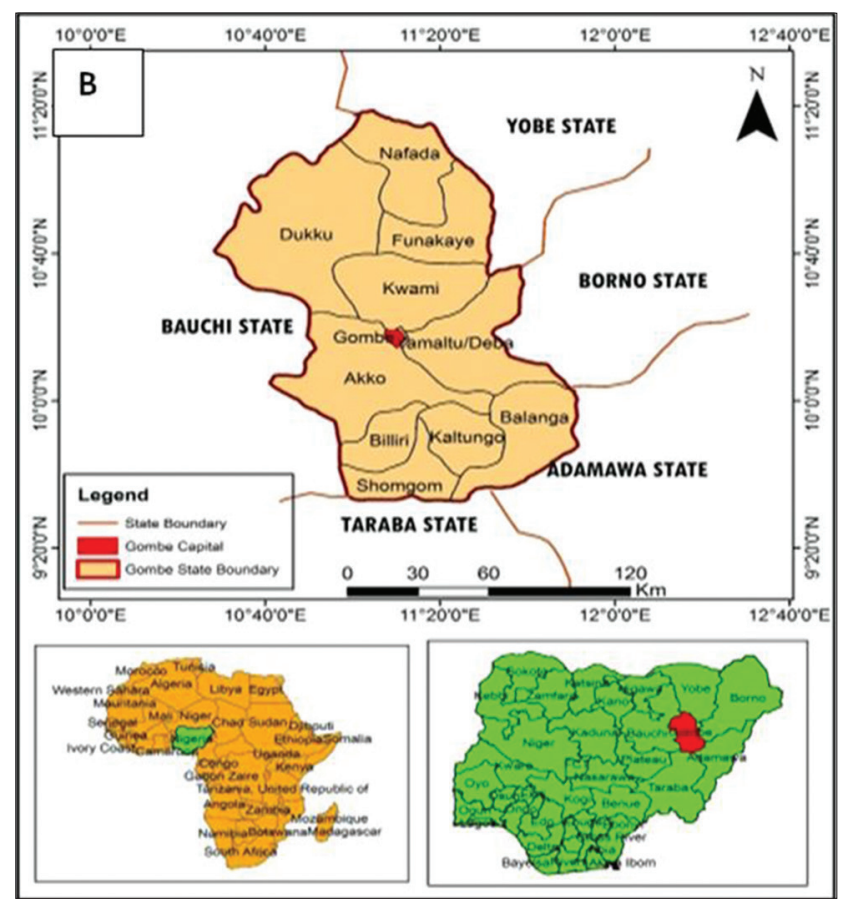

Figure-1: Map of Gombe State showing the study area. 
level of awareness was based on biodata (demographic features), knowledge (zoonotic nature and symptoms of TB in humans), attitude (vaccination status of abattoir staff), and practice (use of protection while handling carcasses). The questionnaire will only be considered valid for analysis by scoring on a scale of " $0-8$ " measurements method as adopted by Waller et al. [29].

\section{Data analysis}

Data were analyzed using Statistical Package for Social Sciences (SPSS) version 20.0. (SPSS 20

Table-1: Demography of the respondents in Gombe township abattoir, Nigeria.

\begin{tabular}{lc}
\hline Variables & Frequencies (\%) \\
\hline Occupation & \\
Animal scientist & $18(16.07)$ \\
Butchers & $55(49.11)^{*}$ \\
Veterinarian & $18(16.07)$ \\
Others & $21(18.75)$ \\
Age (years) & \\
$16-25$ & $29(25.89)$ \\
$26-35$ & $44(39.29)^{*}$ \\
$36-45$ & 18 \\
$>45$ & $21(18.75)$ \\
Gender & $24(21.43)$ \\
Female & $88(78.57)^{*}$ \\
Male & $19(17.12)$ \\
Educational level & $26(23.42)$ \\
None formal & $30(27.03)$ \\
Primary & $36(32.43)^{*}$ \\
Secondary & \\
Tertiary & \\
\hline
\end{tabular}

*Significantly high values
IBM, NY, USA).Chi-square was used to determine the strength of association between variables and $M$. bovis. Odds ratio (OR) and 95\% confidence interval were calculated to measure likelihood and strengths of association between independent variables and bTB (M. bovis). Tables and bar charts were constructed using Microsoft Excel 2010. Values of $p<0.05$ were considered statistically significant.

\section{Results}

Large proportion $(49.1 \%)$ of the respondents were butchers; animal scientists and veterinarians were the least in number (16.1\%). Respondents within the age group 26-35 years were the majority. Male respondent $(78.6 \%)$ and those with tertiary education $(32.1 \%)$ were the majority (Table-1).

A significant number $62(55.4 \%)$ of respondents did not wear protective clothing when being in contact with cattle carcasses (Table-2). 27 (24.1\%) of the respondent consumed unpasteurized milk, and $31.2 \%$ were unaware that consumption of improperly cooked meat is a risk factor to TB (Table-3). Majority $92(82.1 \%)$ of the respondents were aware that bTB is zoonotic in nature. This study showed significant $(p<0.05)$ association between awareness of the respondents of bTB and their educational level, occupational status, and duration of exposure to cattle carcasses with OR of 4.6, 10.0, and 5.0, respectively. However, the likelihood (OR) of being aware of bTB by their level of awareness was higher (4.67) among those with

Table-2: Risk analysis of some variables and other practices during work (use of protective clothing) among abattoir personnel $(n=112)$ in Gombe State.

\begin{tabular}{|c|c|c|c|c|c|}
\hline \multirow[t]{2}{*}{ Variables } & \multicolumn{2}{|c|}{$\begin{array}{l}\text { Used of protective clothing } \\
\text { by respondents }\end{array}$} & \multirow[t]{2}{*}{ OR } & \multirow[t]{2}{*}{$95 \% \mathrm{CI}$} & \multirow[t]{2}{*}{ p-value } \\
\hline & No & Yes & & & \\
\hline \multicolumn{6}{|l|}{ Education } \\
\hline None formal & 14 & 6 & Reference & & 0.009* \\
\hline Primary & 15 & 11 & 1.71 & $0.50,5.87$ & \\
\hline Secondary & 21 & 9 & 1.00 & $0.29,3.44$ & \\
\hline Tertiary & 12 & 24 & 4.67 & $1.43,15.20$ & \\
\hline \multicolumn{6}{|l|}{ Age group (years) } \\
\hline $16-25$ & 12 & 17 & Reference & & 0.204 \\
\hline $26-35$ & 24 & 20 & 0.59 & $0.23,1.52$ & \\
\hline $36-45$ & 13 & 5 & 0.27 & $0.08,0.97$ & \\
\hline$\geq 45$ & 13 & 8 & 0.43 & $0.14,1.37$ & \\
\hline \multicolumn{6}{|l|}{ Gender } \\
\hline Female & 10 & 14 & Reference & & 0.166 \\
\hline Male & 52 & 36 & 0.50 & $0.20,1.24$ & \\
\hline \multicolumn{6}{|l|}{ Occupation } \\
\hline Animal Scientist & 10 & 8 & Reference & & $0.001 *$ \\
\hline Butcher & 40 & 15 & 0.47 & $0.15,1.41$ & \\
\hline Veterinarian & 2 & 16 & 10.00 & $1.76,56.94$ & \\
\hline Others & 10 & 11 & 1.38 & $0.39,4.87$ & \\
\hline \multicolumn{6}{|c|}{ Duration of exposure to cattle carcass (years) } \\
\hline $1-9$ & 19 & 6 & Reference & & \\
\hline $10-19$ & 18 & 4 & 0.70 & $0.17,2.91$ & $0.001 *$ \\
\hline$\geq 20$ & 25 & 40 & 5.07 & $1.78,14.41$ & \\
\hline \multicolumn{6}{|c|}{ Awareness that humans contract TB from cattle } \\
\hline No & 13 & 3 & Reference & & $0.03 *$ \\
\hline Yes & 49 & 47 & 4.16 & $1.11,15.52$ & \\
\hline
\end{tabular}

*Statistically significant values, TB=Tuberculosis 
Table-3: Assessment of respondents' level of awareness of bTB in Gombe, Gombe State, Nigeria.

\begin{tabular}{lc}
\hline Variables & Response (\%) \\
\hline TB can be contracted through direct contact with cattle carcass & $96(85.7)$ \\
Yes & $13(11.6)$ \\
No & $83(74.1)$ \\
Consumption of un-boiled (unpasteurized) milk from cattle is a risk factor of bTB infection & $27(24.1)$ \\
Yes & $73(65.2)$ \\
No & $36(32.1)$ \\
Man cannot be infected with bTB through direct contact with infected organs & \\
Yes & $75(67.0)$ \\
No & $35(31.2)$ \\
Man contract TB through consumption of improperly cooked meat & $101(90.2)$ \\
Yes & $7(6.2)$ \\
No & \\
Yes & $77(68.8)$ \\
No & $33(29.5)$ \\
Wasting, sweating in the night and weakness are signs of TB & $92(82.1)$ \\
Yes & $19(17.0)$ \\
No & \\
TB can be transferred from cattle to human of vice versa & $78(69.6)$ \\
No & $33(29.4)$ \\
TB cannot be cured by treatment with appropriate antibiotics & \\
Yes & \\
No & \\
Yes & \\
No & $35(67)$ \\
\hline
\end{tabular}

$\mathrm{bTB}=$ Bovine tuberculosis

a tertiary level of education (Table-2). Veterinarian respondents had higher (10.0) likelihood of being aware of bTB than other occupational groups (Table$2)$. The majority $(56.5 \%)$ of the respondents had contact with cattle carcass for 20 years and above and are more likely to be aware of bTB $(\mathrm{OR}=5.06)$ than those with less time of exposure (Table-2). However, the majority $(96.7 \%)$ of the respondents believed in the importance of the use of protective clothing while working and 3.3\% did not (Figure-2). Equally, on its zoonotic implications, majority $(82.7 \%)$ knew that bTB could be contracted from cattle as a zoonotic disease. A significant number (80.4\%) of the respondents had received childhood Bacillus Calmette-Guerin (BCG) vaccine, while $14.3 \%$ did not and $5.3 \%$ had no knowledge of their vaccination status (Figure-2). Only $1.8 \%$ of the respondents did not believe that bTB will not cause death, the majority of the personnel are willing to wear personal protective equipments (PPE) (96.4\%) and allow their children receive BCG at childhood $(91.1 \%)$ (Table-4). A significant number (84, $75.7 \%$ ) of the respondents believed that the habit of eating and drinking in abattoir has no harm to human health (Table-4).

\section{Discussion}

bTB still remains an important zoonotic disease of significant impact in developing countries. Although eradicated in most developed nations of the world, it has remained an important source of human infection usually contracted by inhalation of infective droplets, occupational exposure, and uncooked

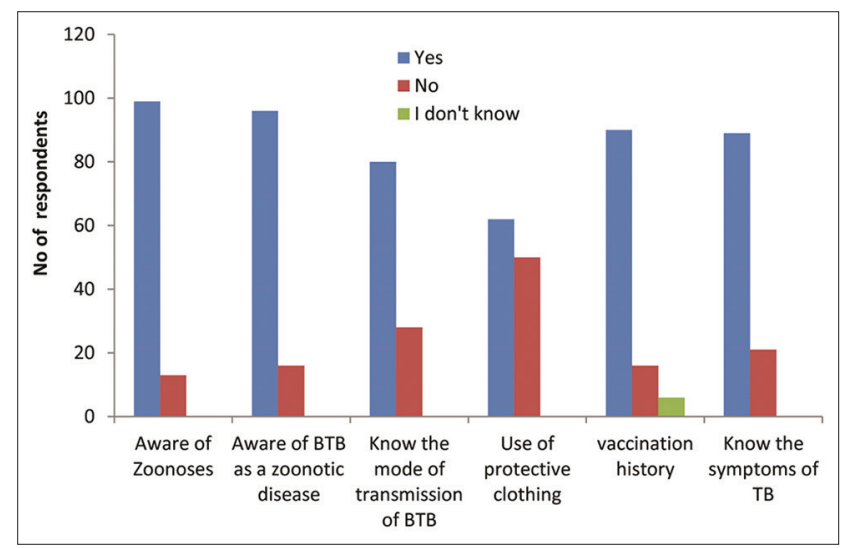

Figure-2: Level of respondents' (abattoir staff) awareness of bovine tuberculosis as a zoonotic disease, in Gombe Township Abattoir, Gombe State, Nigeria.

infected animals' products such as milk. Of these routes, contact with bTB-infected carcasses in the abattoir by personnel and lack of wearing protective clothing by butchers and animal scientists represent important routes of infection in developing countries such as Nigeria.

Various prevalencerates of bTB have been reported from previous studies in Bauchi and Gombe States' abattoirs, revealing higher rate $(9.76 \%)$ of the disease in Gombe state-Northeastern, Nigeria [2, 8].Similarly, other authors reported a pooled prevalence rate of pulmonary tuberculosis $(2.8 \%)$ in cattle slaughtered in Maiduguri, Damboa, Gashua, and Damaturu abattoirs [30], all situated in the Northeastern region of Nigeria. This has further established the endemicity of 
Table-4: Assessment of respondents' attitude toward bTB in Gombe, Gombe State, Nigeria.

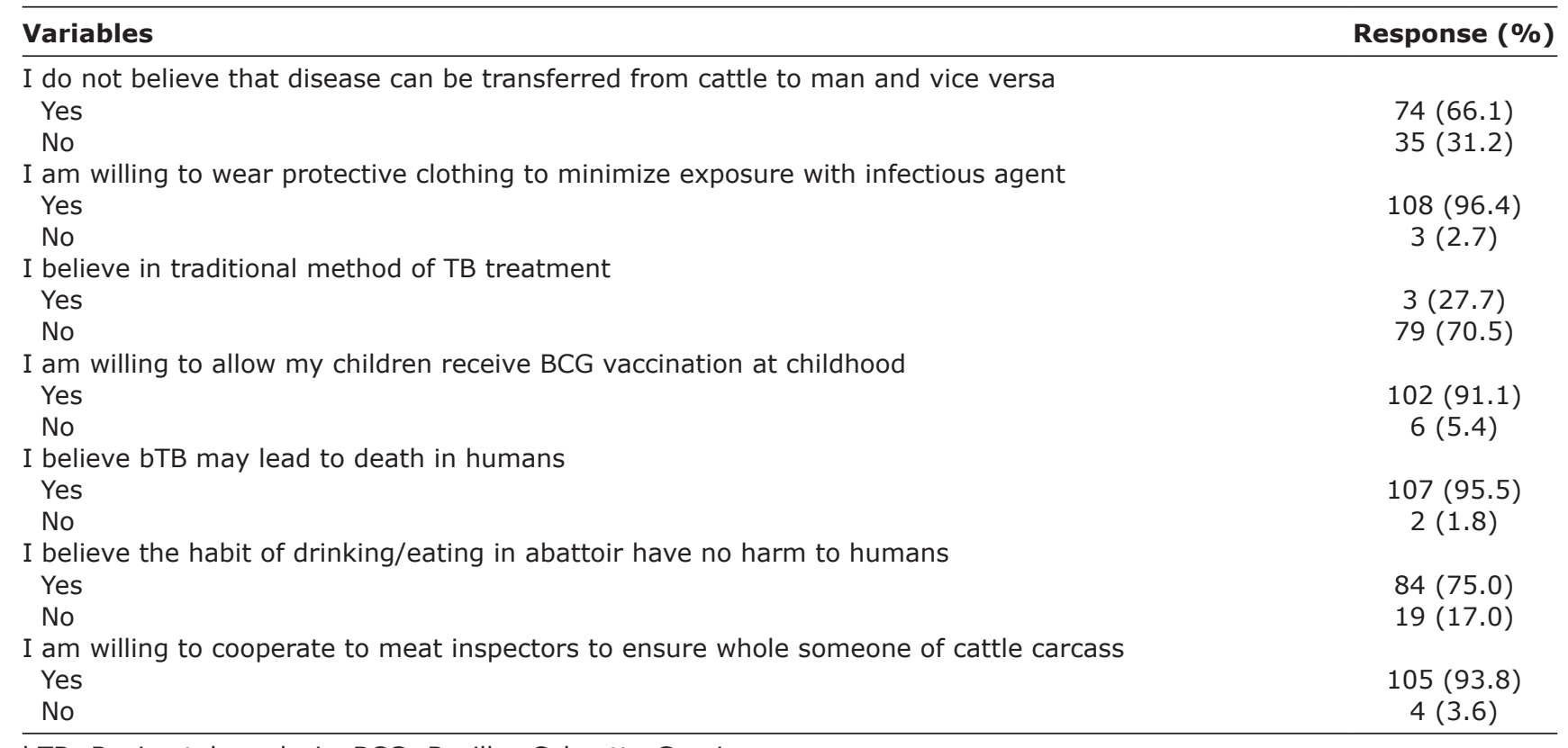

$\mathrm{bTB}=$ Bovine tuberculosis, $\mathrm{BCG}=$ Bacillus Calmette-Guerin

this disease in the northeastern region. Bacteriological isolation of the Mycobacterium is the gold standard best method of arriving at a definitive diagnosis of bTB [30]. This may not be feasible in Sub-Saharan Africa as a result of several reasons. Some of the reasons are: a high cost associated with the culture and isolation of Mycobacterium, are time-consuming, requiring biosafety level 3 containment, and often unsafe in inadequately constructed and ill-equipped laboratories. Gombe State is one of the epidemiological pockets of bTB in Northeastern Nigeria being a confluence state in the zone. Many infected animals may easily come into the state from different sources across the porous interstate borders leading to illegal international trade. This is a major constraint that hinders the effective control strategy and most likely added to the burden of the zoonotic bTB in the region.

Moreover, lack of sustainable national control programs in the country, such as routine tuberculin testing of cattle screening, test-and-slaughter policy, condemnation of affected carcasses at the abattoirs, and full compensation schemes program and detection of bTB is restricted only to the observations of meat inspectors at abattoirs, rather than a sustained surveillance and monitoring with interdisciplinary approach. Therefore, the trend and pattern of zoonotic transmission of tuberculosis from animals to humans in the region are unknown and go unnoticed. Therefore, it is suspected that the prevalence of bTB is underreported due to the subjective nature of gross postmortem examination of affected carcasses by meat inspectors and lack of sustainable disease reporting channel [31].

This survey was conducted with the main aim of assessing the level of awareness and practices of bTB among the abattoir personnel. Most of the respondents are butchers, while veterinarians and other staff are least in number. The public health risk analysis of bTB in this study revealed that many (55.4\%) of the respondents have not been using protective clothing while in contact with cattle, despite the protection it gives against zoonotic disease transmission, clearly increasing their risk of contracting bTB through occupational exposure (Table-1). There was a statistically significant $(p<0.05)$ association between awareness of the respondents (abattoir staff) of bTB and their occupational status, educational level, duration of exposure to cattle carcasses, and their awareness of zoonotic transmission of bTB (Table-5). On the contrary, the age of the respondents was also a determinant of a significant association between awareness of the respondents to the zoonotic bTB as reported by Müller et al. [5]. The disagreement may not be unrelated with the fact that most of the respondent at the time of the interview belongs to the uniform age bracket. The resultant disparities among the age groups are much and statistically not significant to show any association age wise. However, most of the abattoir staff believed in the importance of using protective clothing while working; however, very few of them did not know the importance.

Similarly, on its zoonotic nature, most of them are aware that bTB can be contracted from cattle. Some of the respondents had received prophylactic BCG vaccine at childhood, whereas others did not receive and few did not know their vaccination status. Therefore, this indicates their awareness of bTB and its zoonotic risk. Probably this may be related to awareness and enlightenment generated by other researchers, epidemiological surveys, and relevant sampling and data collection conducted in the study area.

The result from this study on the zoonotic risk associated with the respondents' awareness and 
Table-5: Assessment of respondents' practices toward bTB in Gombe, Gombe State, Nigeria.

\begin{tabular}{lc}
\hline Variables & Response (\%) \\
\hline I will not hesitate or abuse a meat inspector if condemned an organ and carcass & $102(91.1)$ \\
Yes & $8(7.1)$ \\
No & $40(35.7)$ \\
I take fresh unboiled milk & $70(62.5)$ \\
Yes & $102(91.1)$ \\
No & $9(8.0)$ \\
It is necessary to wash your hands with antiseptic after touching live cattle or carcass \\
Yes & $62(55.4)$ \\
No & $14(12.5)$ \\
Protect oneself from the risk of bTB through & $33(29.5)$ \\
Hygienic practice/PPE & $21(18.8)$ \\
Prayer & $87(77.7)$ \\
Use of herbs/concoction & $1(0.9)$ \\
Where you ever been tested for TB & $54(48.2)$ \\
Yes & $53(47.3)$ \\
No & \\
If I encounter Carcass with gross bTB lesion symptoms & 80 \\
I will dispose it off & \\
I will report to authorities & $9(10.11)$ \\
I will sell it & \\
What type of treatment do you prefer for TB & $86(76.8)$ \\
Orthodox & $23(20.5)$ \\
Traditional &
\end{tabular}

$\mathrm{bTB}=$ Bovine tuberculosis, $\mathrm{PPE}=$ Personal protective equipments

practices of bTB is in agreement with the reports by Tigre et al. [32]. However, the socioeconomic impact of the disease burden due to exposure and negligence at the abattoir settings was also consistently in agreement with the report by Cadmus and Adesokan [33] who reported an economic loss of N13, 871,014 per annum with associated public health implications due to tuberculosis $(7.9 \%)$ as major reasons for condemnations in some abattoirs of Southwestern Nigeria. In the same trend, it also agreed with the reports by other researchers $[3,11,34]$ on the management of slaughterhouses in Northern Nigeria, whom in different occasions reported that none of the major abattoirs in Northern Nigeria met the minimum hygienic standards of operation as recommended by the Codex Alimentarius, and they could not support the production of wholesome meat and meat products for human consumption and this contributed to major economic losses.

The statistically significant association between awareness of bTB by the respondents and occupational status found in this study is in agreement with studies by Tigre et al. [32], who conducted a survey on dairy farms in Ethiopia and reported a significant association $(p<0.05)$ between reactor cattle and human TB cases from households as well as the high zoonotic risk of bTB among exposed individuals. Despite awareness of the zoonotic risk by the respondents, there is still a high likelihood of contracting the disease due to exposure, negligence, and underestimation of risk poses by bTB. This is because only a few of the respondents $(44.64 \%)$ used protective clothing. Moreover, there was a significant number (75.7\%) of abattoir personnel reported to have believed that the habit of eating and drinking in abattoir has no any health risks to humans. These attitudes and practices may likely play a vital role in the spread of bTB among abattoir personnel. About $38.8 \%$ of respondents consumed unboiled milk despite the risk of contracting bTB and brucellosis in fresh milk (unpasteurized milk). These findings are in agreement with the report by Tigre et al. [32] who in their study on public health implications of bTB in dairy cattle and dairy farm owners, in South Western Ethiopia, demonstrated that most of the respondents used either raw milk or untreated soured milk, while other respondents consumed mixed (raw and cooked) meat and only few among them were aware that cattle had TB, among which only $85.7 \%$ of them recognized bTB as zoonotic.

The agreements between Ethiopians' and Nigerians' bTB awareness may be attributed to the similarities in their feeding habits and people's lifestyle. However, a recent contrary report from Ethiopian settings contradicts and revealed minimal evidence for zoonotic transmission of $M$. bovis infection [35].

Transmission of bTB from cattle to humans is mainly by ingestion of raw uncooked infected animals' products. There is a significant association $(p=0.001, O R=5.1 ; 95 \% \mathrm{CI}=1.78,14.41)$ between duration of contact of the respondents with a carcass, together with their bad habit of not using protective clothing while handling carcass. Meanwhile, the odds of being infected with bTB due to contact with cattle and lack of compliance to the use of PPEs is 5.1, 
indicating more than 5 times likelihood to come down with the disease as compared to those who are frequently using PPEs when in contact with the possibly infected carcasses $[4,32,34]$. Therefore, this facilitates the zoonotic transmission of bTB from cattle to humans and possibly transmission through inhalation if the contact prolonged. This agreed with the findings of Byarugaba et al. [36], who in their risk assessment study conducted among TB patients from Mbarara a major cattle-rearing region in Uganda identified the species of $M$. bovis responsible for the disease in humans.

\section{Conclusion}

The study revealed that $85.7 \%$ of the respondents were aware of the zoonotic implications of bTB in cattle causing disease in humans. However, only $44.6 \%$ used protection while handling cattle carcasses. This indicated a high risk of exposure to bTB and other endemic zoonotic diseases in the study area. Furthermore, the findings from this study highlighted the urgent need for the intervention of public health authorities in the study area. The risk of bTB transmission as shown by the practices and awareness levels of the abattoir personnel in the study area could be prevented through the use of protective clothing and holistic one-health approaches.

\section{Recommendations}

The government and relevant agencies (non-governmental organizations) should educate and enlighten the public particularly those at risk on bTB preventive measures and enforce the use of protection (PPEs) by all abattoir workers. Public Health expert in the state should be encouraged to bridge the existing gap between public health and bTB awareness.

\section{Authors' Contributions}

SM, ASS and SMJ designed and carried out the survey and wrote the first draft. AMW distributed and retrieved the questionnaires. Data analysis was done by the ASS, SM, and SMJ. PT designed the questionnaire using Epi Info $^{\mathrm{R}}$ V7.2.2.2 Software (CDC, Atlanta, Georgia (US) licensed as public domain). PR and JM searched the related literature and edited the manuscript. All authors read and approved the final manuscript.

\section{Acknowledgments}

The authors are indebted to the Ministry of Animal Husbandry and Nomadic Affairs, Gombe State, and Management of Gombe Township Abattoir and other abattoir staff for their cooperation and assistance during the research fieldwork and also to the MacArthur Foundation center for Veterinary Epidemiology, Ahmadu Bello University, Zaria, Nigeria, for their sponsorship under Grant no: ABU-M.Sc/Vet. $\mathrm{Med} / 53120 / 2012-2013$ ( $\mathrm{N}, 000,000=\$ 16,666.60)$.

\section{Competing Interests}

The authors declare that they have no competing interests.

\section{References}

1. Radostits OM, Blood DC, Hinchey KW, Gray CC. Veterinary Medicine: A Textbook of Diseases of Cattle Sheep, Pigs, Goats and Horses. $10^{\text {th }}$ ed. Philadelphia, PA, USA: Saunders Ltd; 2007.

2. Aliyu MM, Adamu AJ, Bilyaminu YA. Current prevalence of tuberculous lesions among slaughtered cattle in the northeastern state of Nigeria. Rev Elev Vet Pays Des Trop 2009; 62:13-16.

3. Cadmus SI, Adesokan HK, Awosanya AE. Public health issues and observations made during meat inspection at Bodija municipal abattoir, Ibadan, Oyo state, Nigeria. Nig Vet J 2009;29:43-7.

4. Sa'idu AS, Okolocha EC, Dzikwi AA, Gamawa AA, Ibrahim S, Kwaga JK, et al. Public health implications and risk factors assessment of Mycobacterium bovis infections among abattoir personnel in Bauchi state, Nigeria. J Vet Med 2015;2015:5.

5. Müller B, Dürr S, Alonso S, Hattendorf J, Cláudio JM, Sven DC, et al. Zoonotic Mycobacterium bovis induced tuberculosis in humans. Emerg Infect Dis 2013;19:899-908.

6. Alhaji I. Bovine tuberculosis: A general review with special reference to Nigeria. Vet Bull 1976;46:829-41.

7. Cadmus SI, Atsanda NN, Oni SO, Akang EU. Bovine tuberculosis in one cattle herd in Ibadan, Nigeria. Vet Med Czech 2004;49:406-12.

8. Madaki LS, Kudi AC, Abdulkadir I, Salisu I. Prevalence of Bovine Tuberculosis in Slaughtered cattle in Gombe, using Lateral Flow Technique. Unpublished M.Sc Thesis. Nigeria, Zaria: Department of Veterinary Medicine, Faculty of Veterinary Medicine, Ahmadu Bello University; 2012.

9. Ejeh FE, Raji MA, Adeshokan HK, Bello M, Musa JA, Cadmus SI, et al. Current status of bovine tuberculosis in Otukpo, Nigeria. J Anim prod Adv 2014;4:501-7.

10. Adang KL, Kela SL, Sale S. Prevalence of bovine tuberculosis in cattle slaughtered at Gombe township abattoir, Gombe State, Nigeria. J Vet Med Anim Health 2015;10:5897.

11. Sai'idu AS, Mohammed S, Ashafa M, Gashua MM, Mahre MB, Maigado AI. Retrospective study of bovine tuberculosis in Gombe township abattoir, Northeastern Nigeria. Intl J Vet Sci Med 2017;5:65-9.

12. Food and Agriculture Organization. Bovine tuberculosis at the animal-human-ecosystem interface. EMPRES trans bound. Anim Dis Bull 2012;40:2-11.

13. World Health Organization. Global Tuberculosis Control, Epidemiology, Strategy and Financing. Geneva: World Health Organization; 2013. p.1-341.

14. OIE. Office International des Epizooties. Terrestrial Manual 2015. Bovine Tuberculosis. Ch. 1.1. Bovine Tuberculosis (Notification of Diseases, Infections and Infestations, and Provision of Epidemiological Information). Paris, France: By the world assembly of delegates of the OIE; 2015.

15. Idigbe EO, Anyiwo CE, Onwujekwe DI. Mycobacteria in Lagos, Nigeria. J Trop Med Hyg 1986;89:143-8.

16. Wagari A. Review on diagnostic techniques of bovine tuberculosis. Int J Biochem Biophys Mol Biol 2016;1:11-7.

17. Caffery JP. Studies of bovine tuberculosis eradication programme in Europe. Vet Microbiol 1994;40:1-4.

18. CDC. Centre for Disease Control. Mycobacterium bovis (bovine tuberculosis) in humans. Atlanta, Georgia, USAL: CDC Fact Sheet. Centers for Disease Control and Prevention (CDC); 2016. Available from: http://www.cdc.gov/tb/publications/factsheets/general/mbovis.pdf. [Last accessed on 2018 Jul 26].

19. Selim A, El-Haig M, Gaede W. Duplex real-time PCR assay targeting insertion elements IS1081 and IS6110 for 
detection of Mycobacterium bovis in lymph nodes of cattle. Biotech. Anim Husbandry 2014;30:45-59.

20. Zinsstag J, Schelling E, Roth F, Kazwala RR. Economics of bovine tuberculosis. In: Thoen CO, Steele JH, Gilsdorf MF, editors. Mycobacterium bovis Infection in Animals and Humans. $2^{\text {nd }}$ ed. Ames, Iowa, USA: Blackwell Publishing Professional; 2006. p. 68-83.

21. Daborn CJ, Grange R, Kazwala R. The bovine tuberculosis cycle-an African perspective. J Appl Microbiol 1996;81:27-32.

22. Bugwesa ZK, Mbugi EV, Karimuribo ED, Keyyu JD, Kendall S, Kibiki GS. Prevalence and risk factors for infection of bovine tuberculosis in indigenous cattle in the Serengeti ecosystem, Tanzania. BMC Vet Res 2013;9:267.

23. Subbian S, Eugenin E, Kaplan G. Detection of Mycobacterium tuberculosis in latently infected lungs by immunohistochemistry and confocal microscopy. J Med Microbiol 2014;63:1432-5.

24. USDA APHIS. Bovine Tuberculosis Fact Sheet. Available from: https://www.aphis.usda.gov/aphis/ourfocus/animalhealth/animal-and-animal-product-import-information/ ct_organisms_and_vectors. [Last accessed 2018 Aug11].

25. Tschoop R, Abera B, Sourou SY, Guerne-Bleich E, Aseffa1 A, Wubete A, et al. Bovine tuberculosis and brucellosis prevalence in cattle from selected milk cooperatives in Arsizone, Oromia region, Ethiopia. BMC Vet Res 2013;9:163.

26. Wikipedia; 2006. Available from: http://www.en.m.wikipedia/wiki/GombeState. [Last accessed on 2018 Jan 08].

27. NPC; 2006. Available from: http://www.nigeriamasterweb.com/Nigeria06CensusFigs.html. [Last accessed on 2018 Nov 08].
28. FAO. Corporate Documentary Repository, Nigerian Cattle Population; 2010. Available from: http://www.fao.org/ docrep/. [Last accessed on 2018 May 15].

29. Waller J, McCaffery K, Wardle J. Measuring cancer knowledge: Comparing prompted and unprompted recall. $\mathrm{Br} \mathrm{J}$ Psychol 2004;95:219-34.

30. Igbokwe IO, Madaki IY, Danburam S, Ameh JA, Aliyu MM, Nwosu CO. Prevalence of pulmonary tuberculosis lesions in cattle slaughtered in abattoirs in Northeastern Nigeria. Revue Elev Méd Vét Pays Trop 2001;54:191-5.

31. Ejeh, EF, Markus IF, Ejeh AS, Musa JA Lawan FA, Ameh JA, et al. Seasonal prevalence of bovine tuberculosis lesion in cattle slaughtered in Yola abattoirs. Bangladesh J Vet Med 2013;11:113-20.

32. Tigre W, Alemayehu G, Abetu T, Deressa B. Preliminary study on public health implication of bovine tuberculosis in Jimma town, South Western Ethiopia. Glob Vet 2011;6:369-73

33. Cadmus SI, Adesokan HK. Causes and implications of bovine organs/offal condemnations in some abattoirs in western Nigeria. Trop Anim Health Prod 2009;41:1455-63.

34. Bello M, Lawan MK, Aluwong T, Sanusi M. Management of slaughter-houses in Northern Nigeria and the safety of meat produced for human consumption. Food Control 2015;49:34-9.

35. Berg S, Schelling, E, Hailu E, Firdessa R, Gumi B, Erenso G, et al. Investigation of the high rates of extrapulmonary tuberculosis in Ethiopia reveals no single driving factor and minimal evidence for zoonotic transmission of Mycobacterium bovis infection. BMC Infect Dis 2015;15:112.

36. Byarugaba FP, Grimaud S, Godreuil, Etter E. Risk assessment in zoonotic tuberculosis in Mbarara, the main milk basin of Uganda. Bull Anim Health Prod 2010;58:125-32. 